\title{
Prevalence of traumatic dental injuries and role of incisal overjet and inadequate lip coverage as risk factors among 4-15 years old government school children in Baddi-Barotiwala Area, Himachal Pradesh, India
}

\author{
Shipra Gupta ${ }^{1}$, Sanjeev Kumar-Jindal ${ }^{2}$, Mohit Bansal ${ }^{3}$, Anshu Singla ${ }^{4}$ \\ ${ }^{1}$ M.D.S., Associate professor, Department of Periodontology, H.S. Judge Institute of Dental Sciences and Hospital, Chandigarh \\ ${ }^{2}$ M.D.S., Senior Lecturer, Department of Oral Medicine \& Radiology, Rayat Bahra Dental College \& Hospital, Mohali, Chan- \\ digarh \\ ${ }^{3}$ B.D.S., P.G. Student, Department of preventive and community dentistry, M.M. College of Dental Sciences \& Research, Mu- \\ llana, Ambala, India \\ ${ }^{4}$ M.D.S., Senior Lecturer, Department of Pedodontics \& Preventive Dentistry, Rayat Bahra Dental College \& Hospital, Mohali, \\ Chandigarh
}

Correspondence:

Department of Periodontology,

H.S. Judge Institute of Dental Sciences and Hospital, Chandigarh, INDIA

shipra_g26@yahoo.com

Received: 24/08/2010 Accepted: 08/12/2010
Gupta S, Kumar-Jindal S, Bansal M, Singla A. Prevalence of traumatic dental injuries and role of incisal overjet and inadequate lip coverage as risk factors among 4-15 years old government school children in BaddiBarotiwala Area, Himachal Pradesh, India. Med Oral Patol Oral Cir Bucal. 2011 Nov 1;16 (7):e960-5.

http://www.medicinaoral.com/medoralfree01/v16i7/medoralv16i7p960.pdf

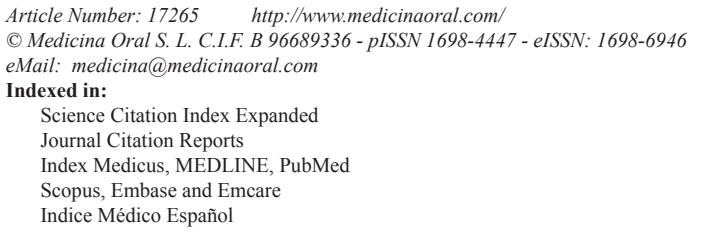

\begin{abstract}
Objective: To assess the prevalence of traumatic dental injuries (TDI) in school children in Baddi- Barotiwala, Himachal Pradesh, India.

Methods: A cross-sectional survey was carried out in Government schools among 1059 government school children aged 4- 15 years. The study was conducted from October 2009 to March 2010 during the school hours. The demographic detail was carried on a structured questionnaire. The data regarding the traumatic injuries was recorded using modified Ellis' classification.

Results: Prevalence of TDI was found to be $4.15 \% .95 .45 \%$ of the injuries were to the maxillary anterior teeth. Maxillary central incisor was the most common tooth to be affected due to trauma (54.5\%). Enamel with dentin fracture with pulp exposure was the main type of TDI (43.1\%). The majority of TDIs were untreated (97.7\%). Falls (54.5\%) were found to be the main cause. Over jet over $3 \mathrm{~mm}$ and inadequate lip coverage were found to be important contributing factors for TDIs.

Conclusion: The present study revealed a relatively low prevalence of dental trauma, but still this figure represents a large number of children. Therefore, educational programs are to be initiated for the community regarding causes, prevention and treatment of traumatic dental injuries. It is crucial to generate considerable efforts to implement health promotion strategies to reverse the observed trends and to provide treatment to TDIs to prevent their biologic and psychological consequences.
\end{abstract}

Key words: Prevalence, traumatic dental injuries, overjet, school children. 


\section{Introduction}

Traumatic dental injuries (TDI) are widespread and have become a serious dental public health problem in childhood (1). There is evidence that the prevalence of TDI is relatively high in many countries. The prevalence of TDIs among adolescents in the Americas and Europe ranged from $15 \%$ to $23 \%$ and $23 \%$ to $35 \%$, respectively $(2,3)$. Corresponding prevalence rates among adolescents in Asia and Africa ranged from $4 \%$ to $35 \%$ and $15 \%$ to $21 \%$ $(4,5)$. Trauma to anterior teeth in the Asia-Pacific region ranged from $6 \%$ to $19 \%$ (6). A review of literature published in 1995 reported the prevalence of TDI on primary teeth worldwide ranged from $4 \%$ to $30 \%$ (7).

The causes of TDIs are well known. The main reported causes of anterior permanent tooth injuries are falls, collisions with people or inanimate object, traffic accidents, sports and violence $(2,8)$. Predisposing factors include inadequate lip coverage and increased incisal overjet of the teeth $(3,6)$.

The majority of dental injuries involve the anterior teeth, which may lead to restriction in biting, difficulty in speaking clearly, and feeling embarrassed to show the teeth. There is agreement that traumatic injuries occur more often to the maxillary than the mandibular incisors and that the central incisors are affected more than the lateral incisors (9).

The problem of the fractured incisor is a perplexing one to the parent, child and especially the dentist. The permanent incisors are important both functionally and aesthetically and the fracture of one or more of these teeth may have psychological effect upon the individual. Physical and psychological discomfort, pain and other complications such as tendency to avoid laughing or smiling which can affect social relationship have been reported as part of the effects which traumatized anterior teeth can cause (10). Dental injury of primary teeth has been found to be responsible of complicated problems to underlying permanent teeth such as hy- poplasia, discoloration, and delay in eruption time and tooth malformation (11).

Furthermore, treatment of TDIs in primary and permanent dentition tends to be neglected $(12,13)$. The majority of the studies to permanent teeth in adolescents were conducted in Europe or the Americas. However, there are too few studies from Asia and Africa. A medline search has shown that a relatively few population based studies have been published regarding TDIs in Indian children. There are no study reports regarding the traumatic injuries among school children in Baddi- Barotiwala area, Himachal Pradesh. Hence this study has been undertaken to assess the prevalence and role of overjet and inadequate lip coverage as risk factors of traumatic dental injuries among 4- 15 years old government school children in Himachal Pradesh, India.

\section{Materials and Methods \\ -Data collection}

A cross-sectional survey was carried out in 14 government schools among 1059 (573 boys and 485 girls) school children aged 4-15 years, in Baddi-Barotiwala region, Himachal Pradesh. The study was conducted from October 2009 to March 2010 during the school hours. The children above the age group of 4 years and who were present on the day of examination were included in the study.

The permission for conducting the study was taken from the District Education Officer, Solan, Himachal Pradesh. Ethical clearance was obtained from the Ethical board committee of Bhojia Dental College \& Hospital, Baddi. Each government school was visited after the prior intimation to the concerned authorities. The consent was taken from the parents two days before the examination. The oral examinations were conducted by a single calibrated examiner, following training for TDI, using a modified version of Ellis's classification (14), Table 1. The trained recording assistant was

Table 1. The modified Ellis's classification (14) and criteria for scoring for TDI.

\begin{tabular}{|c|l|l|}
\hline Code & \multicolumn{1}{|c|}{ Criteria } & \multicolumn{1}{c|}{ Description } \\
\hline 0 & No trauma & Simple fracture of crown, enamel only; involving little or no dentine \\
\hline 1 & Enamel fracture & $\begin{array}{l}\text { Extensive fracture of the crown involving considerable dentine but with no } \\
\text { pulp }\end{array}$ \\
\hline 2 & Enamel and dentine fracture & $\begin{array}{l}\text { Extensive fracture of the crown involving considerable dentine and exposing } \\
\text { pental pulp }\end{array}$ \\
\hline 4 & Non-vital tooth with discoloration & $\begin{array}{l}\text { Traumatized tooth that is non vital and is discoloured, with or without loss } \\
\text { of crown structure }\end{array}$ \\
\hline 5 & Displacement & Extrusion, intrusion or lateral displacement \\
\hline 6 & Total tooth loss & Absence of tooth due to complete ex-articulation \\
\hline 7 & Fracture and restoration & Restored tooth with composite or crown following fracture of crown \\
\hline TDI, Traumatic dental injury & \multicolumn{2}{|l}{} \\
\hline
\end{tabular}

TDI, Traumatic dental injury 
made to sit close enough to the examiner to record the data. The criteria and scoring for TDI is shown in Table 1. The examination was carried out using mouth mirror, explorer and adequate light. The data regarding the demography, type of trauma and other contributing factors like over jet and inadequate lip coverage were recorded on a structured format. Over jet, which was measured using a Community Periodontal Index Probe, was considered a risk factor when it presented values higher than $3 \mathrm{~mm}$. Lip coverage was classified as adequate when lips covered the anterior teeth completely in the at-rest position and as inadequate if the majority of the crown height was exposed and visible.

\section{-Statistical analysis}

The data's were analyzed using SPSS version 13.0. Chi square analysis was used to find the significance of the cross-tabulation of counts of two or more variables. Student t-test (Unpaired) and analysis of variance (ANOVA) were used to find the significance of the cross-tabulation of a variable with the mean of another variable.

\section{Results}

A total of 1059 government school children were examined aged $4-15$ years. The mean age group of the children was $10.3+3.16$ years. $54.1 \%$ of them were boys and
$45.9 \%$ were girls. This cross-sectional survey identified the overall prevalence of TDI to the anterior teeth to be $4.15 \%$. The observed prevalence of dental trauma was higher in boys $(65.9 \%)$ than in girls (34.1\%). 63.6\% of the subjects had at least one tooth with a positive score for dental trauma, including enamel cracks. Detailed results have been shown in table 2 and table 3 .

The most commonly reported cause of injuries to the teeth was falls which contributed to $54.5 \%$, followed by $18.2 \%$ sports related injuries, $9.1 \%$ collisions with inanimate objects like doors and walls, $4.5 \%$ violence and $13.6 \%$ contributed to other causes for example, traffic accidents - cars and motorcycle.

There was a tendency for children with an incisal overjet greater than $3 \mathrm{~mm}$ and inadequate lip coverage to have experienced dental injuries. The results showed that children with an overjet size greater than $3.0 \mathrm{~mm}$ were 5.4 times more likely to present with a dental injury than children with an overjet size equal or lower than $3.0 \mathrm{~mm}$. Finally, children with inadequate lip coverage were 3.4 times more likely to suffer from a traumatic dental injury than children with adequate lip coverage. (Table 3) $43.2 \%$ of the subjects had fractures in enamel and dentin with pulp exposure and while $27.3 \%$ had fractures in enamel and dentin. Other types of TDI such

Table 2. Frequency distribution of 4-15 years old children with TDI by cause of TDI, types of dental injuries, number of teeth injured, tooth involved and age of child. $(\mathrm{n}=1059)$.

\begin{tabular}{|c|c|c|c|c|c|c|}
\hline \multicolumn{7}{|c|}{ According to cause of TDI } \\
\hline & Falls & collision & Traffic incident & Sports related & Violence & \\
\hline Frequency $(\%)$ & $24(54.5)$ & $4(9.1)$ & $6(13.6)$ & $8(18.2)$ & $2(4.5)$ & \\
\hline \multicolumn{7}{|c|}{ According to types of Dental injuries to the teeth } \\
\hline & $\begin{array}{c}\text { Enamel and } \\
\text { Dentine } \\
\text { Fracture }\end{array}$ & $\begin{array}{l}\text { Enamel and dentine } \\
\text { Fracture with Pulp } \\
\text { Exposure }\end{array}$ & $\begin{array}{l}\text { Non-vital tooth with } \\
\text { discoloration }\end{array}$ & $\begin{array}{l}\text { Tooth loss } \\
\text { due to } \\
\text { Trauma }\end{array}$ & & \\
\hline Frequency $(\%)$ & $12(27.3)$ & $19(43.2)$ & $10(22.7)$ & $3(6.8)$ & & \\
\hline \multicolumn{7}{|c|}{ According to the number of teeth involved } \\
\hline & 1 & 2 & 4 & & & \\
\hline Frequency (\%) & $28(63.6)$ & $15(34.1)$ & $1(2.3)$ & & & \\
\hline \multicolumn{7}{|c|}{ According to tooth involved (teeth as represented by FDI nomenclature) } \\
\hline Tooth involved & 11 & 11,12 & 11,21 & 21 & 51 & $51,52,61,62$ \\
\hline Frequency $(\%)$ & $5(11.4)$ & $1(2.3)$ & $9(20.5)$ & $11(25)$ & $4(9.1)$ & $1(2.3)$ \\
\hline Tooth involved & 51,61 & 53 & 61 & 72 & 82 & \\
\hline Frequency $(\%)$ & $5(11.4)$ & $1(2.3)$ & $5(11.4)$ & $1(2.3)$ & $1(2.3)$ & \\
\hline \multicolumn{7}{|c|}{ According to age of child (in years) } \\
\hline Age (years) & 4.0 & 5.0 & 6.0 & 7.0 & 8.0 & 9.0 \\
\hline Frequency (\%) & $3(6.8)$ & $10(22.7)$ & $1(2.3)$ & $2(4.5)$ & $3(6.8)$ & $3(6.8)$ \\
\hline $\begin{array}{l}\text { Cumulative } \\
\text { percentage }\end{array}$ & 6.8 & 29.5 & 31.8 & 36.4 & 43.2 & 50.0 \\
\hline Age (years) & 10.0 & 11.0 & 12.0 & 13.0 & 14.0 & 15.0 \\
\hline Frequency (\%) & $1(2.3)$ & $3(6.8)$ & $2(4.5)$ & $5(11.4)$ & $8(18.2)$ & $3(6.8)$ \\
\hline $\begin{array}{l}\text { Cumulative } \\
\text { percentage }\end{array}$ & 52.3 & 59.1 & 63.6 & 75.0 & 93.2 & 100 \\
\hline
\end{tabular}

TDI, Traumatic dental injury; FDI, Federation Dentaire Internationale; \%, Percentage 
Table 3. Frequency analysis and simple logistic regression of the association between the variables studied and dental trauma in children from 4 to 15 years. $(n=1059)$.

\begin{tabular}{|c|c|c|c|c|c|c|c|}
\hline \multicolumn{8}{|c|}{ Trauma at clinical examination } \\
\hline & Yes & $\mathrm{n}(\%)$ & No & $\mathrm{n}(\%)$ & Total & OR $(95 \% \mathrm{CI})$ & P-value \\
\hline Gender & & & & & & OR for sex (male/ female) & \\
\hline Male & 29 & 65.9 & 544 & 53.6 & 573 & \multirow{2}{*}{$1.670(0.885-3.153)$} & \multirow{2}{*}{0.110} \\
\hline Female & 15 & 34.1 & 470 & 46.4 & 485 & & \\
\hline Are (in vears) & & & & & & $O R$ for aoe $(>10 /<10)$ & \\
\hline$>10$ & 21 & 47.7 & 396 & 391 & 417 & \multirow[b]{2}{*}{$1.425(0.778-2.609)$} & \multirow[b]{2}{*}{0.249} \\
\hline$\leq 10$ & 23 & 52.3 & 618 & 60.9 & 641 & & \\
\hline Overjet & & & & & & OR for overjet $(>3 \mathrm{~mm} /<3 \mathrm{~mm})$ & \\
\hline$\leq 3 \mathrm{~mm}$ & 23 & 52.3 & 869 & 85.7 & 892 & \multirow{2}{*}{$5.47(2.95-10.14)$} & \multirow{2}{*}{0.001} \\
\hline$>3 \mathrm{~mm}$ & 21 & 47.7 & 145 & 14.3 & 166 & & \\
\hline Lip coverage & & & & & & OR (Inadequate/ adequate) & \\
\hline Adequate & 19 & 43.2 & 732 & 72.2 & 751 & \multirow{2}{*}{$3.415(1.85-6.29)$} & \multirow{2}{*}{0.001} \\
\hline Inadequate & 25 & 56.8 & 282 & 27.8 & 307 & & \\
\hline
\end{tabular}

OR: Odds ratio; CI: Confidence interval

as the presence of an enamel crack, discoloration, or sinus tract were comparatively infrequent.

It was found that $63.6 \%$ of the children who had experienced TDI had only one tooth damaged while $34.1 \%$ had two teeth damaged. $95.45 \%$ of the injuries were to the maxillary anterior teeth. Maxillary central incisor was the most common tooth to be affected due to trauma $(54.5 \%)$.

The permanent maxillary central incisors were the most common teeth affected due to trauma accounted for approximately $79.6 \%$, out of which the permanent left maxillary central incisor accounted for $45.5 \%$ of the injuries followed by the permanent right maxillary central incisor with $34.1 \%$.They were closely followed by deciduous left maxillary central incisor $(25 \%)$ and the deciduous right maxillary central incisor $(22.7 \%)$. The prevalence of dental injuries increased with age and was cumulative in nature. The majority of TDIs occurred at home and at school during physical leisure activities such as playing football, running and cycling. Regardless of the dental injuries, it was found that $97.7 \%$ of the subjects did not receive any dental evaluation or control of the problem.

\section{Discussion}

Traumatic dental injuries in children and adolescents have been reported in different parts of the world (15, $16,17,18)$.Variation in prevalence has been related to many factors, such as type of study, trauma classification, sample and diagnostic criteria, limited age groups, and geographic and behavioural differences between study locations and countries (19).
The prevalence of TDIs among adolescents in the Americas and Europe ranged from $15 \%$ to $23 \%$ and $23 \%$ to $35 \%$, respectively $(2,3)$. Corresponding prevalence rates among adolescents in Asia and Africa ranged from 4\% to $35 \%$ and $15 \%$ to $21 \%(4,5)$. Trauma to anterior teeth in the Asia-Pacific region ranged from $6 \%$ to $19 \%$ (6). Our cross-sectional survey identified the overall prevalence of TDI to the anterior teeth among school children aged 4-15 years in Baddi-Barotiwala to be $4.15 \%$. The results were similar to studies conducted by Baldava $P$ and Anup N (20) on adolescent male population in India and by Jose A and Joseph MR (21) on school going children in rural Kerala. They were also similar to the reported 6\% prevalence of TDI in South India, among the examined 838 12-year-old schoolchildren in Kerala, India, by David J et al (15). The overall low prevalence in TDIs in India may be due to the relative lack of outdoor activities and more emphasis on education.

The prevalence of dental injuries increased with age as observed in previous studies by Ferreira JMS et al (18). The fact that the prevalence of dental injury increased with age did not mean that the oldest were the most vulnerable. The characteristics of traumatic injuries mean that the measurement of this type of dental injury is cumulative.

In the present study it was found that the boys are more affected by trauma than girls, which corroborates the findings of other studies by Altun C et al (17), Cavalcanti AL et al (9) and David J et al (15). This may be attributed to the behavioural factors, with the boys tending to be more energetic and inclined toward vigorous outdoor activities as compared to girls. 
In the present study the maxillary central incisors are the most common teeth to be affected by trauma which was found to be similar with the studies done by Ozen B et al (17), David J et al (15) and Ferreira JMS et al (18). The relationship between overjet and dental traumatic injury has been investigated by different authors. Previous studies by Altun C et al (17), Cavalcanti AL et al (9) showed that individuals with an overjet greater than $3 \mathrm{~mm}$ were two and a half times more at risk compared with individuals who had a normal overjet. The results of the present study showed a significant association between the presence of dental trauma and overjet. Individuals with overjet greater than $3 \mathrm{~mm}$ were 5.4 times more at risk compared with individuals who had a normal overjet, corroborating the assertion that the frequency of dental trauma increases proportionally in relation to an increased overjet. Similarly, children with inadequate lip coverage were 3.4 times more likely to have a traumatic dental injury than children with adequate lip coverage. Therefore, as reported by authors, overjet $>3 \mathrm{~mm}$ and inadequate lip coverage are important risk factors of dental trauma.

In the present study, it was found that the injury involving enamel and dentin with pulp exposure and enamel/ dentin was found to be the most common which was similar to the studies as reported by Naidoo S et al (14), Robson F et al (22).

The majority of TDIs occurred at home and at school during physical leisure activities such as playing football, running and cycling. These were the main activities causing children to fall and were related to the aetiology of TDIs. These findings are similar to those in other reported studies Adekoya- Sofowora CA et al (16) and Altun $\mathrm{C}$ et al (17).

According to a survey done among the physical education teachers in Bangalore city of India, Mohandas U and Chandan GD (23) found a lack of knowledge regarding the emergency management of dental trauma. Only $18.4 \%$ of the teachers had received advice regarding the management of avulsive injury, stressing the need for incorporating emergency management of dental injuries in the curriculum of physical education teachers. Parents may lack information concerning the consequences of trauma to the teeth, as $97.7 \%$ of the traumatic injuries in our study, did not result in a professional dental consultation to assess the problem. This finding is similar to a study conducted by Rai SB; Munshi AK (24) on the South Kanara school children. They reported a TDI prevalence of $5.29 \%$, out of which only $1.68 \%$ of the cases with traumatized teeth had undergone treatment. In case of the present study, this may be due to the lack of dental awareness amongst the parents as being an industrial area, the population largely comprises of labourers. Also, their socio-economic status is low and monetary constraints might be a handicap for getting the conservative treatment done.
In light of the results concerning the considerable number of parents who either failed to take measures to minimize possible sequel following a dental injury or had no knowledge about the accident that caused the dental trauma, it is necessary to raise awareness through campaigns that stress the importance of the primary, as well as permanent teeth. It is also necessary to improve access to dental care services. The permanent incisors are important both functionally and aesthetically and the fracture of one or more of these teeth may have psychological effect upon the individual (10). Also, many needs to be done to change the misconception many have regarding primary teeth that "They will be replaced and, therefore, do not require great care.

Information on the prevalence and severity of dental trauma in various age groups of a population has significance for planning public dental care strategies in that population. There is a need to institute a preventive educational program in Baddi- Barotiwala region, directed at parents and school teachers to inform them about TDIs and the benefit of immediate attention to dental treatment. Therefore families and the educational authorities must provide safe environment for children to play such as provision of specific and appropriate public places for sports activities with impact absorbing surfaces which could minimize injuries when children fall. It is also important that children should be supervised while they are playing to minimize the rate at which they fall and sustain TDIs. The use of mouth guards is also recommended for children who are participating in contact sports.

However further studies are required to investigate the personal and social factors that increase the risk of damage to the anterior teeth. Such information is necessary to develop and implement effective preventive strategies for reducing the prevalence and costs of this condition.

\begin{tabular}{|c|c|}
\hline Refel & References with links to Crossref - DOI \\
\hline 1. Marcenes W, al Beirut & N, Tayfour D, Issa S. Epidemiology of \\
\hline traumatic injuries to the 1 & rmanent incisors of 9-12-year-old school- \\
\hline children in Damascus, Sy & ia. Endod Dent Traumatol. 1999;15:117 \\
\hline & \\
\hline Marcenes W, Aless & Causes and preva \\
\hline traumatic injuries to th & rmanent incisors of school childre \\
\hline 12 years in Jaragua do Sul & Brazil. Int Dent J. 2000;50:87-92. \\
\hline 3. Soriano EP, Caldas AF & Ir, Góes PS. Risk factors related to \\
\hline $\begin{array}{l}\text { matic dental injuries in B } \\
2004 ; 20: 246-50 \text {. }\end{array}$ & azilian schoolchildren. Dent Traun \\
\hline 4. Nik-Hussein NN. T & matic injuries to anterior teeth a \\
\hline schoolchildren in Mala & Dent Traumatol. 2001;17:149-52 \\
\hline 5. Hargreaves JA, Matejka & JM, Cleaton-Jones PE, Williams S. Ante- \\
\hline rior tooth trauma in eleven & year-old South African children. AS \\
\hline Dent Child. 1995;62:353-5. & \\
\hline 6. Dearing SG. Overbite, & erjet, lip-drape and incisor tooth \\
\hline in children. $\mathrm{N} Z$ Z Dent $\mathrm{J}$. & $\$ 4 ; 80: 50-2$. \\
\hline 7. Fried I, Erickson P. Ant & ior tooth trauma in the primary dentition: \\
\hline incidence, classificat & eatment methods, and sequelae: a r \\
\hline of the literature. ASI & ent Child. 1995;62:256-61. \\
\hline 8. Soriano EP, Caldas Ade & Jr, Diniz De Carvalho MV, Amorim F \\
\hline
\end{tabular}


ho Hde A. Prevalence and risk factors related to traumatic dental injuries in Brazilian schoolchildren. Dent Traumatol. 2007;23:232-40. 9. Cavalcanti AL, Bezerra PK, de Alencar CR, Moura C. Traumatic anterior dental injuries in 7- to 12-year-old Brazilian children. Dent Traumatol. 2009;25:198-202.

10. Cortes MI, Marcenes W, Sheiham A. Impact of traumatic injuries to the permanent teeth on the oral health-related quality of life in 12-14-year-old children. Community Dent Oral Epidemiol. 2002;30:193-8.

11. Brin I, Fuks A, Ben-Bassat Y, Zilberman Y. Trauma to the primary incisors and its effect on the permanent successors. Pediatr Dent. 1984;6:78-82.

12. De Vasconcelos Cunha Bonini GA, Marcenes W, Oliveira LB, Sheiham A, Bönecker M. Trends in the prevalence of traumatic dental injuries in Brazilian preschool children. Dent Traumatol. 2009;25:594-8.

13. Noori AJ, Al-Obaidi WA. Traumatic dental injuries among primary school children in Sulaimani city, Iraq. Dent Traumatol. 2009;25:442-6.

14. Naidoo S, Sheiham A, Tsakos G. Traumatic dental injuries of permanent incisors in 11- to 13-year-old South African schoolchildren. Dent Traumatol. 2009;25:224-8.

15. David J, Astrøm AN, Wang NJ. Factors associated with traumatic dental injuries among 12-year-old schoolchildren in South India. Dent Traumatol. 2009;25:500-5.

16. Adekoya-Sofowora CA, Adesina OA, Nasir WO, Oginni AO, Ugboko VI. Prevalence and causes of fractured permanent incisors in 12-year-old suburban Nigerian schoolchildren. Dent Traumatol. 2009;25:314-7.

17. Altun C, Ozen B, Esenlik E, Guven G, Gürbüz T, Acikel C, et al. Traumatic injuries to permanent teeth in Turkish children, Ankara. Dent Traumatol. 2009;25:309-13.

18. Ferreira JM, Fernandes de Andrade EM, Katz CR, Rosenblatt A. Prevalence of dental trauma in deciduous teeth of Brazilian children. Dent Traumatol. 2009;25:219-23.

19. Glendor U. Aetiology and risk factors related to traumatic dental injuries-a review of the literature. Dent Traumatol. 2009;25:19-31.

20. Baldava P, Anup N. Risk factors for traumatic dental injuries in an adolescent male population in India. J Contemp Dent Pract. 2007;8:35-42.

21. Jose A, Joseph MR. Prevalence of dental health problems among school going children in rural Kerala. J Indian Soc Pedod Prev Dent. 2003;21:147-51.

22. Robson F, Ramos-Jorge ML, Bendo CB, Vale MP, Paiva SM, Pordeus IA. Prevalence and determining factors of traumatic injuries to primary teeth in preschool children. Dent Traumatol. 2009;25:11822.

23. Mohandas U, Chandan GD. Knowledge, attitude and practice in emergency management of dental injury among physical education teachers: a survey in Bangalore urban schools. J Indian Soc Pedod Prev Dent. 2009;27:242-8.

24. Rai SB, Munshi AK. Traumatic injuries to the anterior teeth among South Kanara school children--a prevalence study. J Indian Soc Pedod Prev Dent. 1998;16:44-51.

\section{Acknowledgments}

The authors thank the school authorities and the children who participated in this study for their co-operation. The authors report no conflict of interest. 